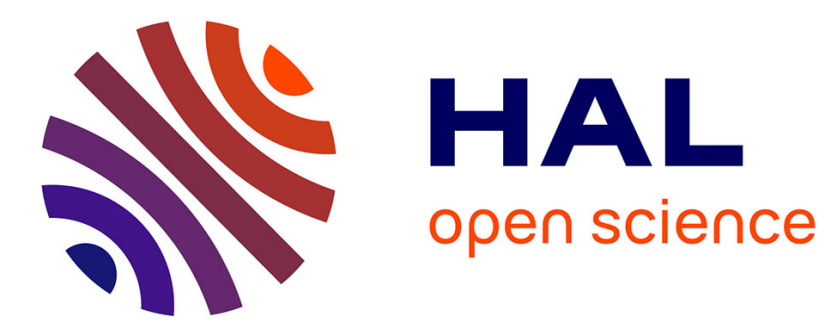

\title{
Ketamine for pain management in France, an observational survey
}

Valéria Martinez, Benoit Derivaux, Hélène Beloeil

\section{To cite this version:}

Valéria Martinez, Benoit Derivaux, Hélène Beloeil. Ketamine for pain management in France, an observational survey. Anaesthesia Critical Care \& Pain Medicine, 2015, 34 (6), pp.357-361. 10.1016/j.accpm.2015.04.005 . hal-01225501

HAL Id: hal-01225501

https://hal-univ-rennes1.archives-ouvertes.fr/hal-01225501

Submitted on 3 Dec 2015

HAL is a multi-disciplinary open access archive for the deposit and dissemination of scientific research documents, whether they are published or not. The documents may come from teaching and research institutions in France or abroad, or from public or private research centers.
L'archive ouverte pluridisciplinaire HAL, est destinée au dépôt et à la diffusion de documents scientifiques de niveau recherche, publiés ou non, émanant des établissements d'enseignement et de recherche français ou étrangers, des laboratoires publics ou privés. 


\title{
Ketamine for pain management in France, an observational survey
}

\author{
Auteurs : Valéria Martinez ${ }^{1}$, Benoit Derivaux ${ }^{2}$, Hélène Beloeil ${ }^{2}$ \\ ${ }^{1}$ Service d'anesthésie-réanimation chirurgicale, hôpital Raymond-Poincaré, AP-HP, université \\ Versailles - Saint-Quentin, 104, boulevard Raymond-Poincaré, 92380 Garches, France \\ 2 Inserm UMR 991, service d'anesthésie-réanimation, CHU de Rennes, université Rennes 1, \\ 35033 Rennes, France
}

Abbreviated title: Ketamine for pain management

Key words: ketamine, postoperative pain, chronic pain, hyperalgesia, survey 


\section{Abstract}

Context: Before updating the French guidelines on postoperative pain treatment in 2015, the Pain Committee of the French Society of Anaesthesiology and Intensive Care (SFAR) conducted a survey on the medical use of ketamine in France.

Methods: An online questionnaire was nationally distributed to members of SFAR, the French Pain Society (SFETD) and the French Society of Emergency Medicine (SFMU). The questionnaire included questions on demographic data, the type of patients for whom ketamine was prescribed, the doses used, the side effects and safety measures associated with the administration of ketamine.

Results: A total of 1,388 questionnaires were analysed. $92 \%$ of the responders declared that they used ketamine. Ketamine was widely used as an anti-hyperalgesic medication but the modalities of administration and the doses varied greatly and were not in accordance with the guidelines. Despite the lack of evidence and guidelines, ketamine has also been used to treat acute and chronic pain. Doses, duration and localization of the patients during administration have varied greatly. Psychedelic effects and hallucinations are the most feared side effects. In terms of monitoring during ketamine infusion, $15 \%$ of physicians declared that no monitoring was necessary while 59\%, 55\%, 59\% and $77 \%$ monitored heart rate, Sp02, blood pressure and level of consciousness, respectively.

Conclusion: Anaesthesiologists have integrated the benefit of ketamine in preventing hyperalgesia but there is no consensus on doses and duration. For other indications (acute and chronic pain treatment), toxicity and the absence of significant benefit call for guidelines from scientific societies. 


\section{Introduction}

In the last ten years, the utilisation of ketamine has greatly changed. It has evolved from a pure sedative/anaesthetic drug to an anti-hyperalgesic drug. Laboratory and clinical investigations have reported the clinical impact of hyperalgesia. It can lead to acute and persistent pain especially after surgery. $(1,2)$ Studies on the pathogenesis of hyperalgesia have clearly shown the benefit of NMDA receptor antagonists, i.e. ketamine at low doses. Ketamine administration decreases morphine consumption and opioid-induced hyperalgesia especially in patients with chronic pain. $(3,4)$ However, reports on the reduction of persistent postoperative pain are scarce and require further study.(5) Moreover, there is no consensus in the literature on an effective regimen in terms of doses and timing.(6) Despite these limitations, publications of studies on the benefit of anti-hyperalgesic ketamine have been followed by widespread use and national societies have published guidelines on the use of ketamine as an anti-hyperalgesic medication.(7)

Ketamine has been used for decades to treat chronic pain. However, studies supporting this indication are scarce. RCTs reporting a benefit of ketamine in reducing chronic pain are desperately lacking(8-10) and guidelines are not available. In this field, the heterogeneity of clinical practices is well known.

In this context, the Pain Committee of the French Society of Anaesthesiology and Intensive Care (SFAR) conducted a survey on the use of ketamine in France. We targeted the three main categories of prescribers: anaesthesiologists, physicians treating chronic pain and physicians in intensive care units and emergency rooms. The results of this survey will be a basis to update French guidelines.

\section{Methods}

The SFAR Pain Committee prepared an online questionnaire and the link was nationally distributed to all the members of the SFAR, the French Pain Society (SFETD) and the French Society of Emergency Medicine (SFMU) using e-mail. It was also available through the 
websites of the societies for 3 months in 2014. The questionnaire included questions (Appendix 1) on demographic data, the type of patients for whom ketamine was prescribed, the doses used, the side effects and safety measures associated with the administration of ketamine. Statistics were performed using Statview ${ }^{\circledR}$. For continuous variables, the mean (SD) is reported unless noted otherwise and for categorical variables, the number of patients in each category and the corresponding percentage are given. Comparisons were made using the $\mathrm{x} 2$ test for categorical variables.

\section{Results}

A total of 1,388 questionnaires were analysed: 740 (55\%) from 3,000 SFAR members, 209 (16\%) from 1,271 SFETD members and 389 (29\%) from 2,648 SFMU members. Among them, $92 \%$ declared that they used ketamine: $97 \%$ anaesthesiologists, $86 \%$ physicians treating chronic pain, $95 \%$ intensive care physicians and $97 \%$ physicians working in emergency rooms used ketamine. Details are provided Table 1. The indications, place of administration and type of patients receiving ketamine varied depending on the physician's speciality.

Among the physicians practicing anaesthesia, ketamine was mostly administered to treat acute pain and as an anti-hyperalgesic medication. Almost all physicians (94\%) administered ketamine to unconscious patients in the operating room or the PACU. They used an intraoperative bolus dose followed by an intraoperative continuous infusion in $46 \%$ of the cases. Doses could vary with a difference up to a 500 factor for continuous infusion with extreme values varying from 0.01 to $5 \mathrm{mg} \cdot \mathrm{kg} \cdot \mathrm{h}^{-1}$ (Table 2).

Among the physicians treating chronic pain, the use of ketamine differed significantly in terms of indication, type of patient and location during administration. Ketamine was mostly used to treat neuropathic pain $(81 \%)$ and cancer pain $(73 \%)$ in conscious patients in the ward and involved older patients. $51 \%$ of the physicians declared that they administered ketamine in palliative care situations. The majority of the physicians administered ketamine with a 
continuous infusion without a bolus dose. As shown in Table 3, the doses varied from 0.001 to $1.2 \mathrm{mg} \cdot \mathrm{kg} \cdot \mathrm{h}^{-1}$ and duration from 2 to 336 hours. The use of oral ketamine was rare but existed with $13 \%$ of the physicians declaring the use of this modality of administration. Our survey did not enable us to describe outpatient ketamine use.

Among the physicians practicing in an emergency room, intensive care or pre-hospital emergency care, ketamine was mostly used to treat acute pain (90\%). Respectively, $57 \%$ and $60 \%$ of the physicians in an emergency room and in intensive care administered ketamine as a sedative/anaesthetic medication. Likewise, $60 \%$ and $84 \%$ of the physicians in an emergency room and in intensive care used ketamine for its anti-hyperalgesic properties. Of the physicians who declared that they administered a bolus (90\%), $34 \%$ could repeat this bolus and the use of a continuous infusion after the initial bolus was more frequent in intensive care $(51 \%)$ than in emergency practice $(30 \%)$.

The most feared side effects were the same (Table 4): psychedelic effects and hallucinations came first. In terms of monitoring during ketamine infusion, $15 \%$ of the physicians declared that no monitoring was necessary while $59 \%, 55 \%, 59 \%, 77 \%$ monitored heart rate, Sp02, blood pressure and level of consciousness, respectively.

Ketamine was used in children by $21 \%$ of the physicians. $29 \%$ of them used specific doses for children.

Only $34 \%$ of the physicians declared working with institutional protocols on ketamine administration. $48 \%$ knew about SFAR guidelines on the use of ketamine as an antihyperalgesic medication.

\section{Discussion}

To our knowledge, this is the first study reporting medical practices on the medical use of ketamine in Europe since the description of the benefit of its anti-NMDA properties at subanaesthetic doses. The main result of this survey was that ketamine is widely used. The 
French observational survey of 200 reported that only $9.2 \%$ of patients received intraoperative ketamine (11). Even if our results reflect the declarative frequency of ketamine used by physicians, our results seemed to show a real change in practice. Its most recent indication, anti-hyperalgesia, has been integrated in daily practice. The other indications were mostly acute and chronic pain. This survey also revealed that practices vary greatly with physicians using ketamine, specifically in terms of dosages, the location of patients during administration and duration of administration.

\section{Ketamine used to prevent hyperalgesia}

Since the initial publications, $(4,12)$ ketamine has been promoted for its anti-hyperalgesic properties. Despite some positive results,(13) its definitive benefit in preventing PPP is still in question, mostly owing to the lack of evidence and the need for further studies.(5) However, intraoperative administration of ketamine can decrease opioid consumption both intraoperatively and postoperatively leading to a decrease in opioid side effects, in particular, postoperative nausea and vomiting $(\mathrm{PONV}) .(14,15)$ In terms of dose and duration, a definitive protocol has not emerged from the literature. In the recent Chaparo et al. review,(5) among the 14 trials they selected, the initial pre-incision loading dose ranged from 0.15 to 1 mg. $\mathrm{kg}^{-1}$ and the total cumulative dose ranged from $1 \mathrm{mg} . \mathrm{kg}^{-1}$ to more than $2 \mathrm{mg} . \mathrm{kg}^{-1}$. The duration of administration varied from intraoperatively only to 24,48 or 72 hours postoperatively. Despite this lack of consensus, the French guidelines on postoperative pain management published in 2009 recommended the following protocol: pre-incision bolus (0.15 to $\left.0.5 \mathrm{mg} . \mathrm{kg}^{-1}\right)$ followed by a continuous intraoperative infusion $\left(0.125\right.$ to $\left.0.25 \mathrm{mg} \cdot \mathrm{kg}^{-1} \mathrm{~h}^{-1}\right)$ if the duration of the surgery is scheduled to be longer than 2 hours. Stopping continuous infusion 30 minutes before the end of surgery was recommended.(7) According to our results, doses of bolus and continuous infusion varied greatly with French physicians. Moreover, $50 \%$ of the physicians administered intraoperative repeated boluses and $17 \%$ administered a continuous IV without a loading dose. No benefit of either protocol has ever been reported. The guidelines were not applied because $48 \%$ of the physicians were not 
aware of their existence but also probably owing to the lack of definitive consensus in the literature. Anaesthesiologists have integrated the use of ketamine in their daily practice and are convinced of its benefit but the modalities of administration are not well known.

\section{Ketamine used to treat acute pain}

The benefit of administering ketamine to treat acute pain is much less documented. Indeed, the mechanisms of action of ketamine do not allow for expectations of an analgesic effect per se. The demonstrated antinociceptive effect of ketamine, called anti-hyperalgesic effect, implies the blockade of NMDA receptors before their activation by an inflammatory stimulus or by opioids. Administering ketamine after NMDA receptor activation by surgery or opioids has not been demonstrated as having any benefit. Ketamine binds to other cellular targets involved in nociceptive pathways. It has been shown to bind to mu opioid receptors and increase the effectiveness of opiate-induced signalling.(16) However, clinical confirmation of benefit is scarce. When compared with acetaminophen after hysterectomy, ketamine was found to be less effective in treating postoperative pain.(17) No published study has reported the benefit of a single ketamine injection to treat postoperative pain. However, a recent metaanalysis collected the data of 7 studies and reported that administering ketamine with morphine improved analgesia and PONV compared with morphine alone.(18) In 4 of the 7 studies, ketamine and morphine were administered via a patient-controlled analgesia (PCA) device. In one study included in the final analysis, morphine and ketamine were administered via an epidural catheter.(19) This study was highly positive showing a strong effect of ketamine and could have influenced the results of the meta-analysis while perimedullar administration of ketamine is not recommended by most national Anaesthesia societies.(20) Moreover, some negative studies are missing from this meta-analysis.(21) It is therefore impossible to draw a definitive conclusion from the most recent meta-analysis. Despite the lack of demonstrated benefit and recommendations of scientific societies, our results showed that $50 \%$ of the physicians in our study used a single injection of ketamine after opioid failure to treat acute pain in the recovery room and in the emergency room. This extension of 
indication of ketamine as an analgesic and not an anti-hyperalgesic medication observed in daily practice needs to be addressed. Indeed, ketamine side effects are not always minor. Arroyo-Novoa et al. described $91 \%$ of the patients with hallucinations or strange sensations when using ketamine associated with morphine compared with morphine alone.(22)

\section{Ketamine used to treat chronic pain}

In chronic pain treatment, ketamine has been used for decades despite a lack of evidencebased proof of benefit. From a mechanistic point of view, persistent NMDA receptor activation can lead to central sensitisation and chronic pain. As an NMDA receptor blocker, ketamine could theoretically stop this central sensitisation and the associated chronic pain. Definitive evidence-based clinical proof is desperately lacking. The last meta-analysis on the benefit of ketamine in cancer pain treatment supported a significant but weak effect (23). When analysing this review in detail, only 5 studies met the criteria for inclusion: 2 concerned perimedullar ketamine and one oral ketamine, one was negative and the only positive study showed a benefit only up to 12 hours after continuous IV ketamine injection. Evidence is clearly lacking. No consensus could be formulated on doses, which varied from 0.05 to 0.5 $\mathrm{mg} \cdot \mathrm{kg} \cdot \mathrm{h}^{-1}$. The evidence of ketamine for the treatment of chronic non-cancer pain, especially syndromes with a neuropathic component, was recently analysed in 2 systematic reviews.( 9 , 10) Current data on short-term infusions indicated that ketamine produces potent analgesia only during administration. Only 3 studies have reported long-term analgesic affects up to 3 months following prolonged infusion (4 to 14 days). However, a return to pre-treatment pain scores was observed.(24-26) None of these studies showed an improvement in quality of life or function. Dose, duration and modalities of administration are still unknown.

Ketamine is therefore currently not recommended as routine treatment for chronic pain. In our survey, the respondents had the opportunity for comments. Several of them asked for recommendations on the subject. Formal guidelines would be impossible to formulate owing 
to the lack of evidence-based data but precautions and limits could be published by scientific societies.

\section{$\underline{\text { Ketamine side effects }}$}

The side effects of Ketamine reported by clinicians have varied from hallucination, nausea/vomiting, sedation, vertigo, tachycardia and hypertension, increased cardiac output to intracranial hypertension. $(9,27)$ A large intra- and inter-individual variability has been observed in the literature and clinicians are unable to predict their occurrence and their severity. This is the reason it would appear to be important to control the use of ketamine outside a secure environment, particularly during administration in a ward or outside a hospital. None of the long-term side effects was reported in our survey even by clinicians who use ketamine to treat patients with chronic pain. The risks of hepatotoxicity, bladder complications and memory defects are probably unknown by most clinicians. Likewise, liver function monitoring has not been reported and more than one out of ten clinicians declared not monitoring anything during ketamine infusion. This practice, which is more likely to be applied by ketamine believers, highlights the urgent need to improve our practice. In addition, such medical ketamine use is evolving toward recreational use in France.(28)

A survey has intrinsic bias that cannot be denied. The possibility of a response bias exists, since those who responded may have been more likely to use ketamine. However, the relatively high number of answers for this type of survey in France could be considered as a good picture of current practice. Another bias is that surveys are inevitably declarative and they might not represent current clinical practice. Finally, some answers to the questions were missing or not appropriate and therefore not presented. This might be due to the ambiguity of some questions or the possibility of free answer.

In conclusion, the results of the survey reinforced the need for updated guidelines on ketamine administration. Hyperalgesia prevention is now part of clinical practice but the 
modalities of ketamine administration need to be further defined. As for acute and chronic pain treatment, the lack of proven benefit and the warnings already published about toxicity call for urgent recommendations and restrictions on the prescription of ketamine for this indication.

\section{Acknowledgements}

Assistance with the study: none

Financial support and sponsorship: none

Conflict of interest: The authors have no conflict of interest to report.

Presentation: Presented as an abstract at the meeting of the French Society of Anaesthesiology and Intensive Care, September 2014 


\section{References}

1. Rivat C, Laulin JP, Corcuff JB, Celerier E, Pain L, Simonnet G. Fentanyl enhancement of carrageenan-induced long-lasting hyperalgesia in rats: prevention by the N-methyl-Daspartate receptor antagonist ketamine. Anesthesiology. 2002;96(2):381-91.

2. Lavand'homme $\mathrm{P}$, De Kock $\mathrm{M}$, Waterloos $\mathrm{H}$. Intraoperative epidural analgesia combined with ketamine provides effective preventive analgesia in patients undergoing major digestive surgery. Anesthesiology. 2005;103(4):813-20.

3. Loftus RW, Yeager MP, Clark JA, Brown JR, Abdu WA, Sengupta DK, et al. Intraoperative ketamine reduces perioperative opiate consumption in opiatedependent patients with chronic back pain undergoing back surgery. Anesthesiology. 2010;113(3):639-46.

4. Joly V, Richebe P, Guignard B, Fletcher D, Maurette P, Sessler DI, et al. Remifentanilinduced postoperative hyperalgesia and its prevention with small-dose ketamine. Anesthesiology. 2005;103(1):147-55.

5. Chaparro LE, Smith SA, Moore RA, Wiffen PJ, Gilron I. Pharmacotherapy for the prevention of chronic pain after surgery in adults. Cochrane Database Syst Rev. 2013;7:CD008307.

6. McNicol ED, Schumann R, Haroutounian S. A systematic review and meta-analysis of ketamine for the prevention of persistent post-surgical pain. Acta Anaesthesiol Scand. 2014;58(10):1199-213.

7. Fletcher $D$, Aubrun F. [Long texts for the formalized recommendation of experts on management of postoperative pain]. Ann Fr Anesth Reanim. 2009;28(1):1-2.

8. Hardy J, Quinn S, Fazekas B, Plummer J, Eckermann S, Agar M, et al. Randomized, double-blind, placebo-controlled study to assess the efficacy and toxicity of subcutaneous ketamine in the management of cancer pain. J Clin Oncol. 2012;30(29):3611-7.

9. Noppers I, Niesters M, Aarts L, Smith T, Sarton E, Dahan A. Ketamine for the treatment of chronic non-cancer pain. Expert Opin Pharmacother. 2010;11(14):241729.

10. Niesters M, Martini C, Dahan A. Ketamine for chronic pain: risks and benefits. Br J Clin Pharmacol. 2014;77(2):357-67.

11. Fletcher D, Fermanian C, Mardaye A, Aegerter P, Pain, Regional Anesthesia Committee of the French $A$, et al. A patient-based national survey on postoperative pain management in France reveals significant achievements and persistent challenges. Pain. 2008;137(2):441-51.

12. Celerier E, Rivat C, Jun Y, Laulin JP, Larcher A, Reynier P, et al. Long-lasting hyperalgesia induced by fentanyl in rats: preventive effect of ketamine. Anesthesiology. 2000;92(2):465-72.

13. Remerand F, Le Tendre C, Baud A, Couvret C, Pourrat X, Favard L, et al. The early and delayed analgesic effects of ketamine after total hip arthroplasty: a prospective, randomized, controlled, double-blind study. Anesth Analg. 2009;109(6):1963-71.

14. Bell RF, Dahl JB, Moore RA, Kalso E. Perioperative ketamine for acute postoperative pain. Cochrane Database Syst Rev. 2006(1):CD004603.

15. Laskowski K, Stirling A, McKay WP, Lim HJ. A systematic review of intravenous ketamine for postoperative analgesia. Can J Anaesth. 2011;58(10):911-23. 
16. Gupta A, Devi LA, Gomes I. Potentiation of mu-opioid receptor-mediated signaling by ketamine. J Neurochem. 2011;119(2):294-302.

17. Faiz HR, Rahimzadeh P, Visnjevac O, Behzadi B, Ghodraty MR, Nader ND. Intravenous acetaminophen is superior to ketamine for postoperative pain after abdominal hysterectomy: results of a prospective, randomized, double-blind, multicenter clinical trial. J Pain Res. 2014;7:65-70.

18. Ding X, Jin S, Niu X, Wang T, Zhao X, Ren H, et al. Morphine with adjuvant ketamine versus higher dose of morphine alone for acute pain: a meta-analysis. Int J Clin Exp Med. 2014;7(9):2504-10.

19. Wong CS, Liaw WJ, Tung CS, Su YF, Ho ST. Ketamine potentiates analgesic effect of morphine in postoperative epidural pain control. Reg Anesth. 1996;21(6):534-41.

20. Beloeil H, Viel E, Navez ML, Fletcher D, Peronnet D, Recommandation formalisee de. [Guidelines for regional anesthetic and analgesic techniques in the treatment of chronic pain syndromes]. Ann Fr Anesth Reanim. 2013;32(4):275-84.

21. Sveticic G, Farzanegan F, Zmoos $P$, Zmoos S, Eichenberger U, Curatolo $M$. Is the combination of morphine with ketamine better than morphine alone for postoperative intravenous patient-controlled analgesia? Anesth Analg. 2008;106(1):287-93, table of contents.

22. Arroyo-Novoa CM, Figueroa-Ramos MI, Miaskowski C, Padilla G, Paul SM, RodriguezOrtiz $P$, et al. Efficacy of small doses of ketamine with morphine to decrease procedural pain responses during open wound care. Clin J Pain. 2011;27(7):561-6.

23. Bell RF, Eccleston C, Kalso EA. Ketamine as an adjuvant to opioids for cancer pain. Cochrane Database Syst Rev. 2012;11:CD003351.

24. Sigtermans MJ, van Hilten JJ, Bauer MC, Arbous MS, Marinus J, Sarton EY, et al. Ketamine produces effective and long-term pain relief in patients with Complex Regional Pain Syndrome Type 1. Pain. 2009;145(3):304-11.

25. Schwartzman RJ, Alexander GM, Grothusen JR, Paylor T, Reichenberger E, Perreault M. Outpatient intravenous ketamine for the treatment of complex regional pain syndrome: a double-blind placebo controlled study. Pain. 2009;147(1-3):107-15.

26. Amr YM. Multi-day low dose ketamine infusion as adjuvant to oral gabapentin in spinal cord injury related chronic pain: a prospective, randomized, double blind trial. Pain Physician. 2010;13(3):245-9.

27. Marland S, Ellerton J, Andolfatto G, Strapazzon G, Thomassen O, Brandner B, et al. Ketamine: use in anesthesia. CNS Neurosci Ther. 2013;19(6):381-9.

28. Gandilhon M, Cadet-Tairou A, Martinez M. Use of ketamine in France: recent trends (2012-2013). http://www.ofdt.fr. 2014. 


\begin{tabular}{|c|c|c|c|c|}
\hline & \multicolumn{4}{|c|}{ Physician speciality } \\
\hline & Anaesthesia & Chronic pain & Emergency room & Intensive care \\
\hline Use of ketamine & $\mathrm{n}=615(97 \%)$ & $\mathrm{n}=163(86 \%)$ & $\mathrm{n}=557(97 \%)$ & $n=471(95 \%)$ \\
\hline Patient $>75$ years & $\mathrm{n}=179(28 \%)$ & $\mathrm{n}=91(49 \%)^{*}$ & $\mathrm{n}=179(29 \%)$ & $\mathrm{n}=133(27 \%)$ \\
\hline Patient with chronic pain & $n=241(38 \%)$ & $\mathrm{n}=146(79 \%)^{*}$ & $\mathrm{n}=128(21 \%)$ & $n=169(34 \%)$ \\
\hline Patient without chronic pain & $\mathrm{n}=286(45 \%)$ & $\mathrm{n}=64(34 \%)$ & $\mathrm{n}=258(42 \%)$ & $n=210(42 \%)$ \\
\hline Awake patient & $n=313(50 \%)$ & $\mathrm{n}=141(75 \%)^{*}$ & $\mathrm{n}=305(50 \%)$ & $n=247(50 \%)$ \\
\hline \multicolumn{5}{|l|}{ Indications: } \\
\hline Hyperalgesia & $n=595(94 \%)$ & $n=66(35 \%)$ & $n=366(60 \%)$ & $n=417(84 \%)$ \\
\hline Acute pain & $\mathrm{n}=609(96 \%)$ & $\mathrm{n}=79(42 \%)$ & $\mathrm{n}=551(90 \%)$ & $n=455(92 \%)$ \\
\hline Chronic pain & $n=212(34 \%)$ & $\mathrm{n}=145(78 \%)$ & $\mathrm{n}=121(20 \%)$ & $n=167(34 \%)$ \\
\hline Narcotic & $\mathrm{n}=388(61 \%)$ & $\mathrm{n}=34(18 \%)$ & $\mathrm{n}=352(57 \%)$ & $n=296(60 \%)$ \\
\hline
\end{tabular}

Table 1: Indications and the type of patients for whom ketamine was used depending on the physician speciality. *Chronic pain" practice vs other types of practice $(P<0.05)$ 


\begin{tabular}{|l|c|c|}
\hline Ketamine for anti-hyperalgesia: & \multicolumn{2}{|c|}{} \\
\hline IV bolus & $\mathrm{n}=869(94 \%)$ & Dosage: $0.49 \mathrm{mg} \cdot \mathrm{kg}^{-1} 0.9$ \\
\hline More than one bolus & $\mathrm{n}=465(50 \%)$ & \\
\hline Continuous IV without any bolus & $\mathrm{n}=142(17 \%)$ & Dosage: $0.24 \mathrm{mg}_{\mathrm{kg}} \mathrm{kg}^{-1} \mathrm{~h}^{-1} \pm 0.6$ \\
\hline Continuous IV after a bolus & $\mathrm{n}=400(47 \%)$ & Dosage: $0.37 \mathrm{mg} \cdot \mathrm{kg}^{-1} \cdot \mathrm{h}^{-1} \pm 0.9$ \\
\hline Ketamine-morphine PCA & $\mathrm{n}=227(26 \%)$ & Duration: $35.3 \pm 16.8 \mathrm{~h}$ \\
\hline Postoperative administration & $\mathrm{n}=305(33 \%)$ & \\
\hline Intraoperative administration only & $\mathrm{n}=392(42 \%)$ & \\
\hline Ketamine for acute pain: & $\mathrm{n}=314(34 \%)$ & \\
\hline Ketamine as the first analgesic choice & $\mathrm{n}=385(42 \%)$ & Dosage: $0.29 \mathrm{mg} \cdot \mathrm{kg}^{-1} \pm 1.2$ \\
\hline After non-opioid analgesics failure & $\mathrm{n}=470(51 \%)$ & \\
\hline After opioids failure & $\mathrm{n}$ \\
\hline Patient location during administration: & $\mathrm{n}=728(79 \%)$ & $/ \mathrm{n}=482(52 \%) / \mathrm{n}=328(35 \%) / \mathrm{n}=237(26 \%)$ \\
\hline OR / PACU / intensive Care Unit / ward &
\end{tabular}

Table 2: Administration of ketamine as an anti-hyperalgesic medication and to treat acute pain. Data are expressed as mean \pm SD. $P C A=$ patient controlled analgesia, $\mathrm{OR}=$ operating room, $\mathrm{PACU}=$ post anaesthesia care unit. 


\begin{tabular}{|l|c|c|}
\hline IV bolus & $\mathrm{n}=158(42 \%)$ & Dosage: $0.42 \mathrm{mg} \cdot \mathrm{kg}^{-1} 0.9$ \\
\hline Continuous IV & $\mathrm{N}=263(73 \%)$ & Dosage: $0.12 \mathrm{mg} \cdot \mathrm{kg}^{-1} \cdot \mathrm{h}^{-1} \pm 0.2$, duration $: 76 \pm 91 \mathrm{~h}$ \\
\hline Per os & $\mathrm{n}=50(13 \%)$ & Dosage: $1.9 \mathrm{mg}^{-1} \pm 2.2$ \\
\hline Patient location during administration: & \\
\hline OR / PACU / Intensive Care Unit / ward & $\mathrm{n}=57(30 \%)$ & $/ \mathrm{n}=54(29 \%) / \mathrm{n}=25(13 \%) / \mathrm{n}=138(74 \%)$ \\
\hline
\end{tabular}

Table 3: Administration of ketamine for chronic pain. Data are expressed as mean \pm SD. OR = operating room, PACU $=$ post anaesthesia care unit. 


\begin{tabular}{|l|c|c|c|c|}
\hline & \multicolumn{4}{|c|}{ Physician } \\
\hline & Anaesthesia & Chronic pain & Emergency room & Intensive care \\
\hline Monitoring: & & & & \\
\hline None & $\mathrm{n}=134(21 \%)$ & $\mathrm{n}=24(12 \%)$ & $\mathrm{n}=63(10 \%)$ & $\mathrm{n}=80(16 \%)$ \\
\hline Heart rate & $\mathrm{n}=303(48 \%)$ & $\mathrm{n}=116(62 \%)$ & $\mathrm{n}=423(69 \%)$ & $\mathrm{n}=263(53 \%)$ \\
\hline SpO2 & $\mathrm{n}=298(47 \%)$ & $\mathrm{n}=54(29 \%)$ & $\mathrm{n}=449(73 \%)$ & $\mathrm{n}=263(53 \%)$ \\
\hline Arterial blood pressure & $\mathrm{n}=307(49 \%)$ & $\mathrm{n}=123(66 \%)$ & $\mathrm{n}=421(69 \%)$ & $\mathrm{n}=256(52 \%)$ \\
\hline Consciousness & $\mathrm{n}=456(72 \%)$ & $\mathrm{n}=131(70 \%)$ & $\mathrm{n}=506(82 \%)$ & $\mathrm{n}=384(78 \%)$ \\
\hline Side effects: & \multicolumn{4}{|c|}{} \\
\hline Psychedelic effects & $\mathrm{n}=501(79 \%)$ & $\mathrm{n}=127(68 \%)$ & $\mathrm{n}=473(77 \%)$ & $\mathrm{n}=397(80 \%)$ \\
\hline Hallucinations & $\mathrm{n}=434(67 \%)$ & $\mathrm{n}=108(58 \%)$ & $\mathrm{n}=433(70 \%)$ & $\mathrm{n}=339(68 \%)$ \\
\hline Arterial hypertension & $\mathrm{n}=105(17 \%)$ & $\mathrm{n}=71(38 \%)$ & $\mathrm{n}=159(26 \%)$ & $\mathrm{n}=90(18 \%)$ \\
\hline Tachycardia & $\mathrm{n}=107(17 \%)$ & $\mathrm{n}=54(29 \%)$ & $\mathrm{n}=161(26 \%)$ & $\mathrm{n}=102(21 \%)$ \\
\hline Intracranial hypertension & $\mathrm{n}=98(16 \%)$ & $\mathrm{n}=26(14 \%)$ & $\mathrm{n}=161(26 \%)$ & $\mathrm{n}=85(17 \%)$ \\
\hline Sedation & $\mathrm{n}=130(21 \%)$ & $\mathrm{n}=66(34 \%)$ & $\mathrm{n}=221(36 \%)$ & $\mathrm{n}=127(26 \%)$ \\
\hline Vigilance decrement & $\mathrm{n}=193(31 \%)$ & $\mathrm{n}=92(49 \%)$ & $\mathrm{n}=278(45 \%)$ & $\mathrm{n}=177(36 \%)$ \\
\hline
\end{tabular}

Table 4: Side effects and monitoring. Data are expressed as mean SD. 